\title{
Global High-Power Rectenna Site Selection
}

\author{
Oleg Nizhnik \\ Department of JST, ERATO Human-Sensing Fusion Project, \\ Open Labs Bld., 8111, Shosha 2167, Himeji-shi, Hyogo-ken, Japan
}

Received 2012-07-22, Revised 2012-08-27; Accepted 2012-08-28

\begin{abstract}
The reasons for implementing a high power density $\left(>1 \mathrm{~kW} / \mathrm{m}^{2}\right)$ terrestrial rectenna for a space power plant system are described. The physical limitations on rectenna implementation are outlined and formal criteria for the rectenna site selection are proposed. The best site found was Mikura-jima, Japan.
\end{abstract}

Keywords: Rectenna, Power Satellite, Solar Satellite, Site Selection, Land Footprint

\section{INTRODUCTION}

Orbital solar power generation is the most powerful, sustainable and scalable power source available for humans on Earth. Ultimately, as soon as all other power generation options, including fusion and solar power conversion on the Earth's surface reach their respective limits, the transition to orbital power stations (solar or fusion) is inevitable. However, that time of transition may not be easy because orbital power generation and transmission belongs to the class of the mega-projectsthe technology does not scale effectively down to megawatt power levels because of the necessity of a large, continuously receiving rectenna array. Securing a rectenna site in the future may be increasingly difficult as Earth surface use becomes more and more intensive. Therefore, it would be better to secure the best sites for rectennaspresently, while such sites are relatively available. Building a pilot rectenna in one of these sites may be one of the best ways to avoid wasting of the site on other,short-sighted purposes.

Orbital power generation has 3 main advantages compared with the terrestrial equivalents:

- The higher solar power density and reliability available in space. In particular, the solar power density at geostationary orbit averages 0.95 Sun (Fig. 1), while in countries such as Japan, the incident solar power density averages 0.13 Sun (Sekihara and Kano, 1957)

- The minimal possible ecological impact of the power generation. With a rectenna capable of converting $70 \%$ (Wie and Roithmayr, 2005) of the incoming beam power to electric energy, the waste heat is smaller than for any other conceivable electrical power generator. Because all other ecology-damaging factors of electrical power generation beside waste heat can be eliminated in principle, the ultimate electrical power generation technology will be limited by its waste heat percentage

- The possibility of a high power density on the rectenna site. High power densities facilitate a smaller land footprint compared with terrestrial solar farms

\subsection{The Economics of Orbital Power Plant}

Solar power harvesting in orbit has significant differences from the land-based analogue; a comparison is provided in Table 1.

The costs per watt of a solar farm can be expressed as:

$\mathrm{C}=\frac{\mathrm{C}_{\text {constr }}+\mathrm{C}_{\text {land }}+\mathrm{C}_{\text {storage }}}{\mathrm{P}_{\text {density }} \cdot \eta_{\text {conv }} \cdot \mathrm{t}_{\text {operation }}}$

In Equation 1, the main cost contributors are the construction cost, the cost of the lost productivity of the land and the cost of the energy storage systems required to compensate for the unreliability of the energy source (Lewis and Nocera, 2006).

Overall, orbital solar power generation is advantageous only if the unreliability of the land-based solar farms cannot be cheaply compensated for, or if the total cost of the solar farm is dominated by the cost of the lost productivity of the land. Both cases are not true as in 2012, but future increase of the population density may result in both increases in land prices and difficulty in compensating for diurnal and seasonal variations of the output of the land-based solar farms because of the lack of storage reservoirs such as hydro-storage systems and large-scale chemical energy storage proposed in (Lewis and Nocera, 2006). 


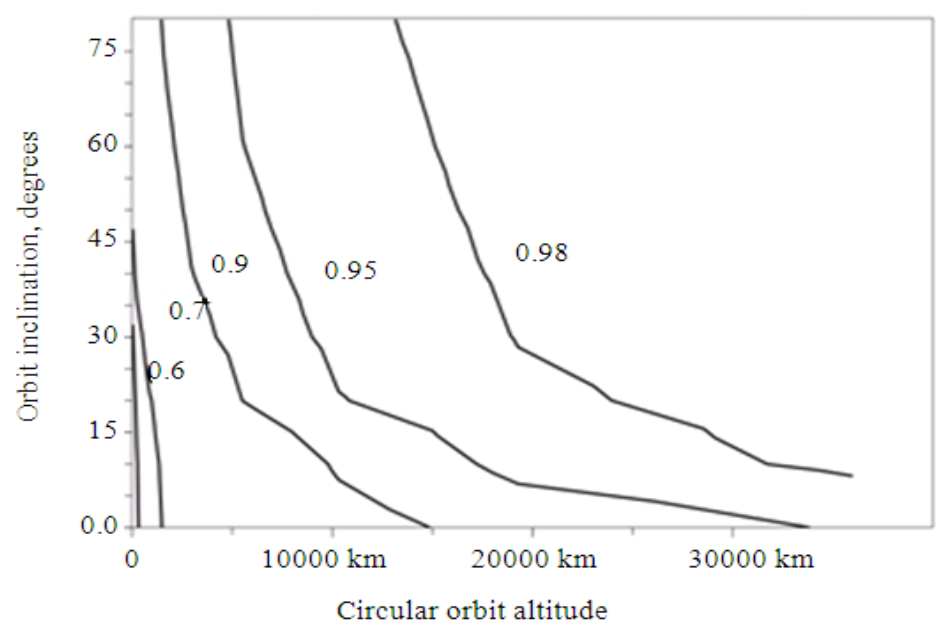

Fig. 1. Available average irradiation on Earth circular orbits as a function of orbit height and inclination (in the units of the Suns (1 Sun $=1.4 \mathrm{kWm}^{-2}$ )

Table 1. Comparison of the orbital and land-based solar power farms

\begin{tabular}{lll}
\hline Factor & Orbital solar plant & Land-based solar plant \\
\hline Power density & 0.95 Sun on GEO (Fig. 1) & 0.13 Sun (Sekihara and Kano, 1957) \\
Degradation mechanism & Radiation damage ( 10 years to & $\begin{array}{l}\text { Corrosion and dusting } \\
\text { ( 30 years to failure) }\end{array}$ \\
& $50 \%$ degradation) & $16 \%$ (photovoltaic) (Chapman \\
Power efficiency & $10.7 \%$ (solar concentrator), 7\% (photovoltaic) & et al., 1979) \\
& (Patha and Woodcock, 1974) & $3 \mathrm{USD} / \mathrm{W}$ (Komoto et al., 2009) \\
Construction costs in 2012 & $80 \mathrm{USD} / \mathrm{W}$ (Summerer, 2012), assuming & $\sim 50 \mathrm{~km}^{2} / \mathrm{GW}$ \\
Land footprint & GEO delivery cost 21000 USDkg \\
Reliability & $\sim 2 \mathrm{~km}^{2} / \mathrm{GW}$ & $>60 \%$ downtime \\
\hline
\end{tabular}

In the future, the conditions for the cost-effectiveness of orbital solar (or fusion) power generation will be met in the most densely populated areas with low levels of solar irradiation.

\subsection{Fundamental Limits of Rectenna}

To select the optimal rectenna site, the fundamental limitation on incoming microwave beam parameters and the rectenna itself should be considered and these limitations are discussed below.

\subsection{Operating Frequency}

Raising the operating frequency of the rectenna provides significant advantages. As frequency increases, the waste heat disposal is simplified and the voltage on each rectifier is reduced (Brown, 1987). Additionally, the size (and the construction cost) of the rectenna and the minimal size of the transmitting antenna are also reduced. However, DC-to-microwave and microwave-toDC conversion becomes less efficient anda microwave beam is more readily scattered by the precipitation in the lower atmosphere.
Scattering by raindrops is a fundamental problem with high-power beams, not fixable by technology. Raindrop scattering may result in microwave-oven-like power densities tens of kilometres from the rectenna. Severe disruption of wireless links is also possible up to $300 \mathrm{~km}$ around the rectenna site. Therefore, the beam frequency must be selected to avoid raindrop scattering. Although the individual raindrops scatter microwave energy roughly proportional to the 4 th power of the raindrop size, because of the complex actual distribution of raindrop sizes in rain, the actual scattering dependence on the frequency is nearly linear (Das et al., 2010) with a well-definedcutofffrequency. According to (Das et al., 2010) the cutoff is close to the $10 \mathrm{GHz}$ for a rainfall rate of $10 \mathrm{mmh}^{-1}$ and $6 \mathrm{GHz}$ for a rainfall rate of $100 \mathrm{mmh}^{-1}$. Below the cutoff frequency, the scattering at zenith is approximately $0.05 \mathrm{~dB}$. Because the most intensive rain is concentrated in the lower $4 \mathrm{~km}$ of the air column (Paulius and Dias, 2012) with a sharp cutoff above, the rainscattered power of a microwave beam above cutofffrequency can be expressed as Equation 2:

$$
\mathrm{P}_{\mathrm{s}}=\mathrm{P}_{\text {in }}\left(0.01+0.025\left(\mathrm{f}-\mathrm{f}_{\text {cut }}\right) /\left(10^{9}\right)\right) / \cos \left(\mathrm{J}_{\text {zenith }}\right)
$$


According to (Paulius and Dias, 2012), the vertical extent of the rain is 2-3 times higher in arid and mountainous zones, further enhancing scattering and the radius of the area affected by scattering.

Because a $10 \mathrm{mmh}^{-1}$.rainfallrate in temperate zonesaccounts for $2.7 \%$ of the total rainfall time (Xin and Arthur, 2012), operating a rectenna above the $10 \mathrm{GHz}$ frequency will result in frequent, region-wide electromagnetic interference events. Therefore, if a rectenna is designed for the frequencies above $10 \mathrm{GHz}$, it must be located in a precipitation-free region, i.e., a desert. Because the energy consumption in desert regions is also negligible (with the exception of the Nile delta and the Arabian peninsula), a high-power rectenna for the frequencies above $10 \mathrm{GHz}$ could not be considered. Furthermore, rectennas re-radiate some of the incident energy at the harmonics of the input frequency, predominantly at the 2nd harmonic of the input frequency. Although the higher-harmonic radiation can be suppressed down to $1 \%$ of the incident power (Brown, 1987), it is advisable to prevent raindrop scattering of the 2nd harmonic of the incoming beam as well. Therefore, the frequency of the high-power terrestrial rectenna should be limited to $5 \mathrm{GHz}$ to avoid electromagnetic interference issues regardless of the capabilities of the transmitters and the rectifiers.

\subsection{SidelobeLevel}

Current beam-forming technologies may achieve$60 \mathrm{~dB}$ levels in the sidelobes. Therefore, around each rectenna it is advisable to have an exclusion zone at least as wide as the rectenna itself to avoid harm from the nearest sidelobe and to have a margin against beam pointing errors.

\subsection{Power Density Level}

As can be observed from Fig. 1, the most technically appealing solution for the power satellites may be power satellites constellation on the highly-inclined medium Earth orbit (altitudes of approximately8000 km). These orbits offer approximately 0.9 Sun average irradiance while having lower radiation levels (Ganushkina et al., 2011) compared with a geostationary orbit. Rectennas (or alternatively, power satellites sizes) can be 4-8 times smaller compared with power satellites beaming from geostationary orbit. However, power satellites on medium Earth orbits must switch their power between many countries, so an extensive power rectenna and power cable network is necessary to utilize the full capacity of power satellites. Such a project will clearly require much tighter global economic integration than currently exists and is therefore unfeasible without severe changes to the social network of mankind. A simplified system with only 2 receiving stations and satellites in medium Earth orbit (Summerer, 2012) is useful only for supply during daily power consumption peaks. Therefore, to deliver power to single country, only 24-hour orbits for power satellites can be considered at the present time.

\subsection{For a Rectenna, 3 Factors Limit the Achievable Power Density}

The runaway heating of the ionosphere by the microwave beam (Duncan and Gordon, 1977), the waste heat dissipation capability andthe breakdown voltage of the individual rectifiers.

The safe microwave power in ionosphere is 200 $\mathrm{Wm}^{-2}$ (Duncan and Gordon, 1977; Brown, 1987). The JAXA is aware that thermal runaway of the ionosphere poses fundamental limits on the delivery of RF power from orbit. Therefore, an orbital experiment to validate the maximal ionospheric power levels is planned (Susumu, 2009). If a single-beam rectenna is to be used, as it was assumed in all previous designs, the beam power density on the rectenna will not exceed the ionospheric power density limit. This power density is nogreater than that found in land-based solar farms in many regions of the world. Taking into account the much larger construction cost of an orbital power plant compared to a land-based solar farm (as expressed in Table 1, 80 USD/W versus 3 USD/W), a single-beam rectenna does not result in land use reduction compared to solar farms. Multiple power generation satellites in variously inclined 24-h circular orbits will increase the maximal power density at the rectenna to:

$$
\frac{\mathrm{dP}}{\mathrm{dS}}=\left(\frac{\mathrm{dP}}{\mathrm{dS}}\right)_{\mathrm{i}} \cdot 2 \pi\left(\frac{\mathrm{h}_{\mathrm{i}}}{\mathrm{r}_{\text {rectenna }}}\right)^{2} \sin \left(\phi_{\max }\right) \sin \left(\theta_{\text {max }}\right)
$$

Each satellite in such orbits, from the point of view of ground observer, will move in the sky in a figure-eight path and to fill the (elliptic) area of sky uniformly the satellites with extreme arguments of orbits $\theta \in\left[\theta_{0}-\theta_{\max } ; \theta_{0}+\theta_{\max }\right]$ should have lower orbital inclinations $\mathrm{j} \in\left[-\mathrm{j}_{\max } ; \mathrm{j}_{\max }\right]$. The latitude of a rectenna is also somewhat important because at higher latitudes, thearea of the heated area of the ionosphere increases because of the slanting angle of the incident beam, increasing the total power dissipated in ionosphere (but not the dissipated power density). Furthermore, the north-south dimension of a rectenna must be extended at higher latitudes.

Assuming the maximal distance from an orbital power generator to a rectenna is $40000 \mathrm{~km}$, the maximal 
diameter of the power generation transmitter is $1 \mathrm{~km}$, the beam-forming penalty (central lobe broadening) factor is equal to 3 andthe microwave beam frequency is $5 \mathrm{GHz}$ as derived in section 1.3 , the minimal rectenna radius can be expressed as:

$$
\mathrm{r}_{\text {rectenna }} \geq \frac{\mathrm{R}_{\text {orbit }} \mathrm{K}_{\mathrm{bf}} \mathrm{c}}{2 \mathrm{fD}_{\text {transmitter }}}
$$

and the minimal rectenna radius is equal to the $3.6 \mathrm{~km}$. Such a rectenna could theoretically accept up to $0.97 \mathrm{TW}$ (at the equator) of power from microwave beams without risking the runaway heating of the ionosphere. For more realistic systems utilizing a power generators constellation at inclinations up to 30 degrees anda rectenna located at 40 degrees latitude, the maximal accepted power will be 156 $\mathrm{GW}$, resulting in average power density at the rectenna equal to $3.8 \mathrm{kWm}^{-3}$. The plot of the rectenna maximal received power as a function of the latitude is shown in Fig. 2.

Another fundamental rectenna limitation is the waste heat. Ideally, a high power density rectenna would dump the waste heat to the largest radiator available-the ocean in the non-poisonous form of hot water. For a hypothetical $100 \mathrm{GW}$ beam power and a rectenna efficiency of $70 \%$ (Patha and Woodcock, 1974), 30GW of thermal energy must be disposed of. Air radiators are not an economical option because their output power is limited to $2 \mathrm{kWm}^{-2}$ for a case temperature 100 degrees above ambient, while higher temperatures make operation extremely unsafe because of the hot steam clouds appearing after any rain. Furthermore, air radiators do not scale up to gigawatt power levels well, because at low wind speeds a "heat island" will rapidly develop over the rectenna site. Water cooling is more efficient, safe and a widely used solution, but requires a source of fresh, low-carbonate water to operate. Even a simple plate with film boiling can dissipate up to 20 $\mathrm{kWm}^{-2}$ and require a water supply of approximatelyK $\mathrm{K}_{\mathrm{cool}}$ $=40 \mathrm{mln}$. tons $/\left(\mathrm{GW}^{*}\right.$ year $)$. Both desalinized sea water and river water can be used, with river water being the cheapest option. If river water is used as the coolant, the required river drainage basin will be $1000 \mathrm{~km}^{2} \mathrm{GW}^{-1}$ for a relatively wet climate with precipitation of $1 \mathrm{ton} / \mathrm{m}^{2}$ and a drainage factor 0.4 , if $\mathrm{K}_{\text {cool }}=1.3 \mathrm{GJ} /$ ton (corresponding to boiling, 1MPa pressurized $180 \mathrm{C}$ water at the cooler output). Therefore, for a multi-GW rectenna an average-size river nearby is desirable. If no large river is available, a reverse-osmosis desalinization plant must use electric energy equal to approximately $1 \%$ (Wade, 2001) of the waste heat to be dissipated to produce cooling water from seawater. To prevent heat island formation in the ocean as well, the rectenna coolers must discharge in deep waters with the strong, stable currents. The effects on the marine life will be similar to those of low-intensity geothermal vents.

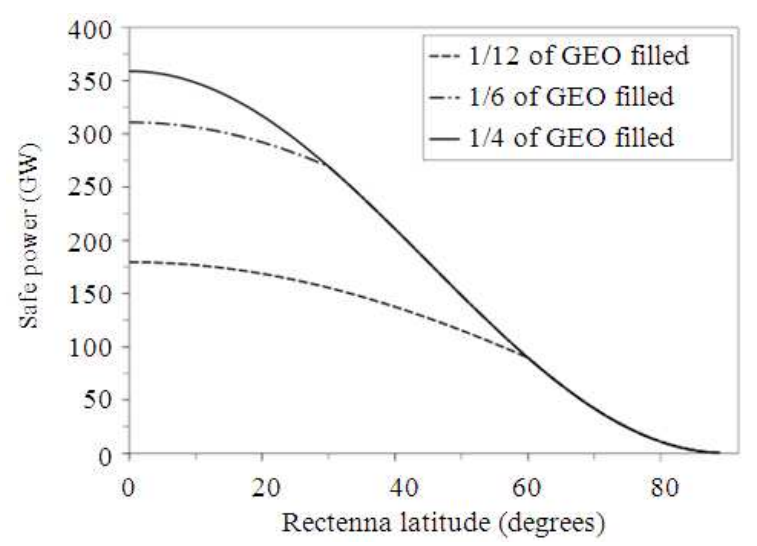

Fig. 2. Safe rectenna beams power as a function of geographical latitude

The voltage limitation on RF power rectifiers can be expressed as Equation 3:

$\mathrm{V}_{\mathrm{pp}}=\sqrt{[\mathrm{c} /(2 \mathrm{f})]^{2} 8 \mathrm{Z}_{\text {dipole }} \mathrm{P}_{\text {rect }} / \mathrm{S}_{\text {rect }}}$

For $\mathrm{Z}_{\text {dipole }}=120 \mathrm{Ohm}$ (Wade, 2001) and an incident power density of $3.8 \mathrm{~kW} / \mathrm{m}^{2}$ at $5 \mathrm{GHz}$, the peak-to-peak voltage for an individual rectifier may reach $57 \mathrm{~V}$. Therefore, $100-\mathrm{V}$ rated rectifiers will provide more than enough performance for the any implementable $5-\mathrm{GHz}$ rectenna array. The interference fading resulting from the destructive interference between beams from the different power satellites will result in the actual voltage most of the time being lower than the limit calculated from (3). To effectively absorb most of the incident power in the presence of the interference fading, the rectenna must be multi-layered. While most of the power will be absorbed in the outer dipole layer, sporadically non-coherent RF power will leak into the lower layers. The total thickness of the rectenna dipole layers must exceed 1 wavelength $(6 \mathrm{~cm}$ at $5 \mathrm{GHz})$ to absorb the noncoherent RF beams efficiently (analogous to the criteria of light absorption by thin metal layers near the plasma frequency of metal).

One more possible bottleneck for space power system implementation is the attitude control of the large solar power satellites. The "abacus" configuration of a $10-\mathrm{km}^{2}$ solar array in geostationary orbit will consume approximately 85 tons of xenon per year (Wie and Roithmayr, 2005)- double the world production in 2005. Even using so a lot of propellant, the beam pointing error still can be up to $63 \mathrm{~km}$, making necessary a gigantic receiving array. Therefore, a passively-stabilized (Sasaki et al., 2007) or a symmetric (Wie and Roithmayr, 2001) solar satellite design should be seriously considered. 
Table 2. The summary parameters of the possible 1st generation space power generation system with physical constraints applied

\begin{tabular}{ll}
\hline Parameter & Value \\
\hline Solar satellites diameter & $2 \mathrm{~km}$ \\
Solar satellite output power & $0.36 \mathrm{GW}$ \\
Number of solar satellites in constellation & 425 \\
Combined microwave power at rectenna site & $169 \mathrm{GW}$ \\
Rectenna diameter & \\
(for $2 \mathrm{~km}$ transmitter diameter) & $>3.6 \mathrm{~km}$ \\
Rectenna waste heat & $51 \mathrm{GW}$ \\
Water coolant flow & $39 \mathrm{ton} / \mathrm{s}$ \\
Power delivered to the grid & $118 \mathrm{GW}$ \\
\hline
\end{tabular}

The extremely high estimated construction cost and construction time of the orbital power constellation indicates that the orbital delivery and power generation technologies are not yet ready for the task of the orbital power plant construction. Therefore, the following section will concentrate on the rectenna site selection and reservation. Any possibility of actually implementing the orbital power satellites and rectenna is pending significant advances in technology or demandfrom society. The reference rectenna design based on the limitations discussed in this section is shown in Table 2.

\subsection{Figure-of-MERIT of Rectenna Site}

The comprehensive analysis of the rectenna site selection factors was performed in the (Chapman et al., 1979), which listed 58 factors, 34 of them being unique to the rectenna. In (Chapman et al., 1979) it was concludedthat the most limiting factor is the contradictory requirement to have a large population density in order to consume the rectenna energy locally and a low population density for the rectenna site clearance. In 1979, when (Chapman et al., 1979) was written, it was not obvious that land-based solar arrays might be a primary competing technology to orbital power systems. In 2012, solar farms are a proliferating business, although still heavily subsidized. However, problems are already appearing with the voluminous energy storage requirements or the large land footprints (Lewis and Nocera, 2006) of land-based solar arrays. The land lot clearance cost is subject to multiple factors. Therefore a formal cost estimation approach suitable for algorithmic implementation is necessary to evaluate the merits of the rectenna sites worldwide.

Extremely simplified, the long-term cost of the area designated for power generation is assumed to be the cost of the lost economic productivity of the displaced persons. Therefore, a simple relation can be written to estimate a merit of a given site for rectenna placement Equation 4:
$\mathrm{T}_{\text {payoff }}=\frac{\left(\mathrm{K}_{\text {safety }} \mathrm{C}_{\text {men }} \sigma_{\text {men }}+\mathrm{C}_{\text {rectenna }}\right) \mathrm{S}_{\text {rectenna }}(\alpha)}{\mathrm{P}_{\text {net }} \mathrm{C}_{\text {el }}}$

The payoff time of less than 50 years is normally required to start construction.

In the previous section, requirement for a safety margin around the rectenna results in an area safety factor $\mathrm{K}_{\text {safety }}=9$. It is assumed that the rectenna field will cost $\$ 120 \mathrm{M}$ USD per sq. $\mathrm{km}$, equal to the cost of a largescale solar farm. The cost to displace any person from the building area is assumed to be \$1M USD per person up to densities of 10-20 persons/sq. $\mathrm{km}$. In a humanrights oriented country displacing a population from a more densely populated area is unrealistic because of the public protests. However, high power network output requires a large population nearby to consume the electricity, creating a fundamental contradiction for the site selection. The competition from land-based solar farms (which can be tailored with finer granularity to fit the local needs) presents an additional challenge. Ideally, the target site must have an uneven population density with small areas devoid of population and the remaining areas heavily populated to prevent the deployment of (or make insufficientinsufficient) large-area land-based solar arrays.

Substituting the numerical value for the electricity buy price $\left(0.3 \$ / \mathrm{kWh}=\$ 2630 \mathrm{M} \mathrm{USD} / \mathrm{GW}^{*}\right.$ year, then (2) can be written as Equation 5:

$\mathrm{T}_{\text {payoff }}=\frac{\mathrm{C}_{\text {total }}}{\mathrm{C}_{\text {land }}} \frac{\left(9 \sigma_{\text {men }}+120\right) \cdot 40.7}{2630 \mathrm{P}_{\text {net }} \cos \left(\alpha+\phi_{\max }\right)}$

For the rectenna design and the costs summarized in Table 1, the payoff time can be expressed as Equation 6:

$\mathrm{T}_{\text {payoff }}=\frac{7 \cdot 10^{6}}{5000} \frac{366.3 \sigma_{\text {men }}+4884}{310340} \approx\left(1.65 \sigma_{\text {man }}+22\right) / \cos \left(\alpha+\phi_{\max }\right)$

With a realistic range of population densities, the payoff time of the land allocation will be 22-39 years. Therefore, if a rectenna were to be built today, it would pay off in one generation. However, according to the calculation of the build time of the orbital part of the overall power generation system, current space launch technology, orbital solar panel technology and highpower microwave transmitter technology are not sufficiently advanced to facilitate the implementation of the orbital power generation and delivery systems in a reasonable period of time.

Therefore, the question is not whether to build a rectenna (because the power source for a multi-GW rectenna cannot be built with current technology and low-power rectennas are not competitive with solar farms) but rather where to allocate sites for the rectenna development in the future. 


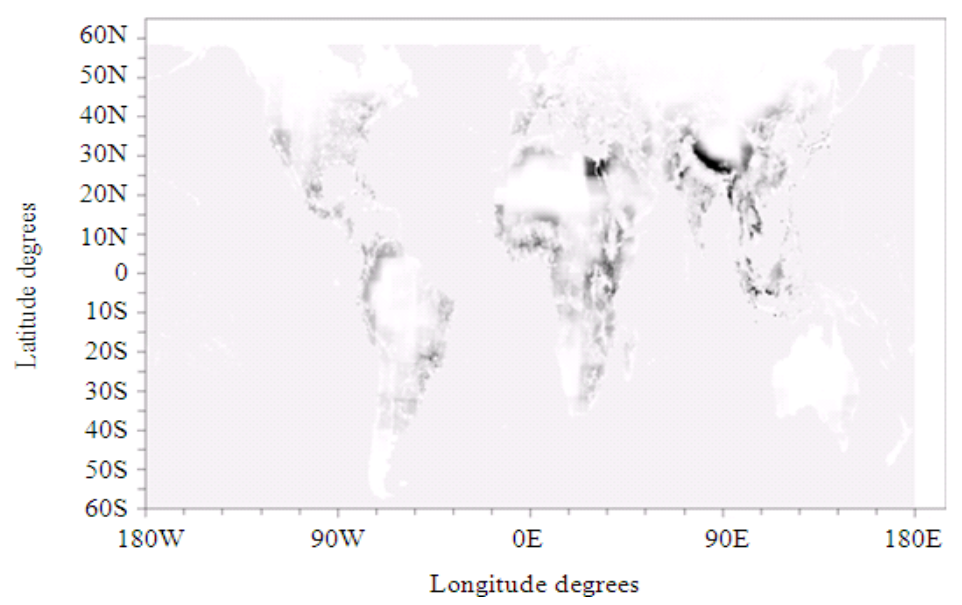

Fig. 3. The map of the rectenna site figure-of-merit (payoff time) based on the population density database. Area with higher figure-ofmerit are darker

Because global energy consumption is currently increasing $2.3 \%$ per year (Lewis and Nocera, 2006), it is only question of time before the largest, most densemetropolitan areas will exhaust all other energy sources and will be forced to rely on high-power-density rectennas.

Because the economical-size rectenna will produce hundreds of GW of grid power, the population of nearby energy consumers will be a limiting factor to rectenna output during the early stages of operation. Therefore, site Figure of Merit (FOM) can be written as:

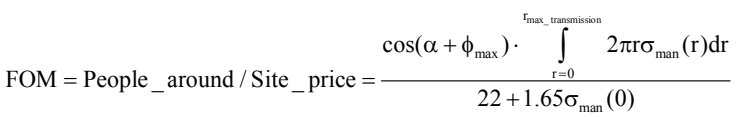

Equation (7) favors the uninhabited areas close to the large cities in the equatorial zone.

\subsection{Algorithm for Rectenna Site Search}

The algorithm for the rectenna site estimation must use a worldwide population density database and an insolation database to estimate the potential of the any given site for the rectenna and a land-based solar power plant. If asite hasa good FOM according to eq. 7 and the surrounding area has a solar farm potential much below $100 \mathrm{GW}$, than that site is the primary candidate for the rectenna site. The primary population density database used

was (http://sedac.ciesin.columbia.edu/gpw/global.jsp), which has a grid resolution of $1 / 4$ degree of arc. The insolation database (http://opensolardb.org) was interpolated and gridded to the same resolution.

For each non-marine grid position in the population density database a square "box" extending $1000 \mathrm{~km}$ by latitude and $1000 \mathrm{~km}$ by longitude was selected. The population in all database elements falling within the $1000 \times 1000 \mathrm{~km}^{2}$ box was summed instead of using the radius-based integral in equation 7 and the rest of the equation 7 was applied without modifications. The same summing procedure was carried out for the insulation database using a minimal monthly value of insolation for each database point within the $1000 \times 1000 \mathrm{~km}^{2}$ box. The selection of minimal values instead of average values is reasonable if (as the author believes) the increasing power consumption of mankind in the future will make any long-term, large-scale energy storage too dangerous or impossible.

The results of the rectenna FOM calculations is shown in Fig. 3.

The data showed in Fig. 3 was further processed to obtain the top 25, widely separated sites. Also, landbased solar farm potential was calculated for each region centered on the site (Table 3). The processing algorithm was as follows.

Select the site with maximal figure of merit from the FOM map. Put the site with maximal figure of merit in the site list. Nullify in the FOM map the FOMs of all locations within each $1000 \times 1000 \mathrm{~km}^{2}$ box, centeredat the location with the current maximal FOM. This is done to prevent excessive clustering of the found sites.

\subsection{The Potential Rectenna Sites}

The semi-automatically generated rectenna site list provided in Table 3 diverges strongly from the manually selected sites. In particular, no high-merit sites were identified in the USA and Indonesian sites found were concentrated in the west of the country, contrary to the results in (Purwanto and Collins, 2004). 
Table 3. The potential rectenna sites

\begin{tabular}{|c|c|c|c|c|c|}
\hline $\mathrm{N}$ & Lat. $\mathrm{N}$ & Lon. E & $\begin{array}{l}\text { Merit } \\
\text { (reverse payoff } \\
\text { time) }\end{array}$ & Location & $\begin{array}{l}\text { Solar } \\
\text { potential, } \\
\text { TW }\end{array}$ \\
\hline 1 & 24.25 & 118.50 & 9591 & Kinmen, Taiwan & 5.300 \\
\hline 2 & 28.25 & 86.00 & 9124 & Bungamati, China-Nepal border & 7.600 \\
\hline 3 & 30.50 & 80.75 & 8167 & Burang, China-India border & 4.900 \\
\hline 4 & -3.75 & 112.00 & 7276 & Sampit, Indonesia & 7.000 \\
\hline 5 & 21.50 & 93.00 & 6537 & Paletwa, Myanmar & 9.600 \\
\hline 6 & -3.25 & 106.25 & 6348 & TulungSelapan, Indonesia & 5.900 \\
\hline 7 & 27.75 & 92.00 & 6128 & Tawang, China-India border & 7.800 \\
\hline 8 & 13.75 & 104.50 & 5356 & KulenPromtep, Cambodia & 8.200 \\
\hline 9 & -9.00 & 114.50 & 5048 & Kendalrejo, Indonesia & 1.900 \\
\hline 10 & 28.25 & 34.50 & 4937 & Sharm el-Sheikh, Egypt & 6.400 \\
\hline 11 & 27.00 & 71.25 & 4538 & Jaisalmer, India & 8.200 \\
\hline 12 & 5.50 & 101.50 & 4458 & Hulu Perak, Malaysia & 6.900 \\
\hline 13 & 2.00 & 32.00 & 4451 & Kabarega National Park, Uganda & 15.800 \\
\hline 14 & 32.00 & 69.25 & 4152 & ZarghunShar, Afghanistan & 3.800 \\
\hline 15 & 27.00 & 29.25 & 4102 & West of Asyut, Egypt & 8.700 \\
\hline 16 & -3.00 & 38.25 & 4037 & Tsavo West National Park, Somalia & 9.000 \\
\hline 17 & 33.50 & 132.25 & 4027 & Sadamisaki Peninsula, Japan & 0.520 \\
\hline 18 & 15.00 & 118.00 & 3593 & Scarborough Reef, Philippines (disputed) & 2.200 \\
\hline 19 & 3.50 & 36.75 & 3582 & Lake Turkana, Kenya & 14.500 \\
\hline 20 & 18.50 & 104.50 & 3474 & Bolikhamsai, Laos & 10.700 \\
\hline 21 & 34.00 & 139.50 & 3461 & Izu islands, Japan & 0.035 \\
\hline 22 & -20.25 & -46.50 & 3424 & East of Uberaba, Brazil & 9.400 \\
\hline 23 & 29.25 & 101.00 & 3251 & Garze, China & 7.000 \\
\hline 24 & 7.50 & 11.25 & 3009 & Gashaka-Gumti National Park & 12.500 \\
\hline 25 & 11.25 & 35.50 & ??? & Benishangul-Gumuz, Ethiopia & 10.000 \\
\hline
\end{tabular}

Table 4. Evaluation of the Mikura-jima as high-power rectenna site

\begin{tabular}{|c|c|}
\hline & Advantages \\
\hline 1 & Sufficient size and shape, $20.5 \mathrm{~km}^{2}$ and slightly elongated north-to-south \\
\hline 2 & Low residential population (351 in 2009) \\
\hline 3 & $\begin{array}{l}\text { Tokyo-Kansai agglomeration, totaling } 80 \mathrm{mn} \text {. people, } 200 \mathrm{~km} \text { to the north-within } \\
\text { the reach of the modern high-power submarine cables (Ackermann, 2005) }\end{array}$ \\
\hline 4 & $\begin{array}{l}\text { Location of the Honshu island (main consumer of the rectenna power) in temperate zone with large variations } \\
\text { in solar insolation. }\end{array}$ \\
\hline 5 & $\begin{array}{l}\text { No densely populated areas up to } 150 \mathrm{~km} \text { around, allowing ample margin for the travel exclusion } \\
\text { zone and RF interference zone }\end{array}$ \\
\hline 6 & Availability of the deep ocean for the coolant discharge at the site. \\
\hline 7 & Availability of permanent ocean current to carry away a waste heat. \\
\hline \multicolumn{2}{|r|}{ (1) } \\
\hline & $\begin{array}{l}\text { Low amounts of freshwater avallable; therefore, desalinization plant will be required } \\
\text { to produce the cooling water. }\end{array}$ \\
\hline 2 & $\begin{array}{l}\text { The rough terrain of the island, rearranging up to } 3 \text { billion tons of bedrock may be } \\
\text { necessary to sufficiently flatten the site. }\end{array}$ \\
\hline 3 & The small size of the existing seaport; therefore, a very extensive upgrade in deep waters will be required. \\
\hline 4 & $\begin{array}{l}\text { The large biodiversity on and around Mikura-jima, especially the presence of the endemic species on the } \\
\text { island. Because the conservation of wildlife on the high-power rectenna site is close to impossible, } \\
\text { the rectenna constructionwill result in extinctions, unless endemic species are re-introduced elsewhere. }\end{array}$ \\
\hline
\end{tabular}

These results can be explained by the preference in the algorithm given to higher energy consumer count at the expense of a reduction in the rectenna site safety margin. Manual selection, conversely, tends to overlook suitable sites if these are too small (less than $5 \%$ of the search area size), thus favouring more remote, sparsely populated locations.

A comparison of the top 25 sites is given in Table 3 for the rectenna reference design in Table 1. The results show a single site where a large power demand is combined with an extremely low potential for landbased solar power. This is site No. 21-the Izu archipelago off the coast of Honshu, Japan. Among the several islands in the archipelago, most must be ruled out because of the insufficient size or active volcanism, leaving only one rectenna site candidateMikura-jima. An analysis of the merits of Mikura-jima is provided in Table 4. 


\section{CONCLUSION}

An analysis of orbital power generation and transmission to Earth using a microwave beam and a high-power density rectenna was performed. Although the orbital part of the power generation system is found to be too costly to implement with current technology, the potential superior compactness and efficiency of the rectenna power receiver compared with all other conceivable energy technologies may merit the implementation of the orbital power generation and transmission system in the future whenthe power deficit will raise the price of electricity sufficiently. Therefore, the analysis was conducted to identify the locations where a rectenna will be most useful in the scenario of the unbounded growth of global power consumption but with the capability of the high-power cable transmission limited to $500 \mathrm{~km}$. The population density pattern (and hence the power consumption pattern) of 2010 was assumed. Only 2 feasible locations worldwide were identified, both located in Japan. The most suitable location found was Mikura-jima (suitable for rectenna with a net power $35 \mathrm{GW}$ or more). The second, albeit marginal location found was the Sadamisaki Peninsula (suitable for a rectenna with net power $520 \mathrm{GW}$ or more). All other potential sites were found to have landbased solar farm development potential far exceeding that of a safe rectenna. Therefore, it is proposed to restrict development of the Mikura-jima until construction of the rectenna there isapproved or until it can be proved that the technology for orbital power generation and microwave transmission to Earth will never be implemented for some reason.

\section{REFERENCES}

Ackermann, T., 2005. Chapter 22. Transmission systems for offshore wind farms. Wind Power Power Syst. DOI: $10.1002 / 0470012684 . \operatorname{ch} 22$

Brown, W.C., 1987. Rectenna Technology Program: Ultra light $2.45 \mathrm{GHz}$ rectenna $20 \mathrm{GHz}$ rectenna. NASA Astrophysics Data System.

Chapman, P.K., B.J. Bugos, K.I. Csigi, P.E. Glaser and G.R. Schimke, 1979. Assessment of economic factors affecting the satellite power system. Volume 2: The systems implications of rectenna siting issues. NASA Technical Reports Sever (NTRS).

Das, S., A. Maitra and A.K. Shukla, 2010. Rain attenuation modeling in the $10-100 \mathrm{GHz}$ frequency using drop size distributions for different climatic zones in tropical India. Progress Electromag. Res. B, 25: 211-224. DOI: 10.2528/PIERB10072707
Duncan, L.M. and W.E. Gordon, 1977. Ionosphere/microwave beam interaction study. NTRS.

Ganushkina, N.Y., I. Dandouras, Y.Y. Shprits and J. Gao, 2011. Locations of boundaries of outer and inner radiation belts as observed by Cluster and Double Star. J. Geophysical Res., 116: 1-18: DOI: 10.1029/2010JA016376

Komoto, K. M. Ito, P. Van DerVleuten, D. Faiman and K. Kurokawa, 2009. Energy from the Desert: Very Large Scale Photovoltaic Systems: Socio-economic, Financial, Technical and Environmental Aspects. 1st Edn., Earthscan Publications Ltd., London, ISBN10: 1844077942 , pp: 190.

Lewis, N.S. and D.G. Nocera, 2006. Powering the planet: Chemical challenges in solar energy utilization. PNAS, 103: 15729-15735. DOI: 10.1073/pnas.0603395103

Patha, J.T. and G.R. Woodcock, 1974. Feasibility of large-scale orbital solar/thermal power generation. J. Spacecraft, 11: 409-417. DOI: 10.2514/3.62089

Paulius, O. and J. Dias, 2012. Satellite estimates of precipitation-induced dissipation in the atmosphere. Science, 335: 953-956. DOI: 10.1126/science.1215869

Purwanto, Y. and P. Collins, 2004. A preliminary case study for rectenna sites in Indonesia. Proceedings of the 4th International Conference on Solar Power from Space, Jun. 30-Jul. 2, ESA Special Publications, Granada, Spain, pp: 287-294.

Sasaki, S., K. Tanaka, K. Higuchi, N. Okuizumi and S. Kawasaki et al., 2007. A new concept of solar power satellite: Tethered-SPS. Acta Astronautica, 60: 153165. DOI: 10.1016/j.actaastro.2006.07.010

Sekihara, K. and M. Kano, 1957. On the distribution and variation of solar radiation in Japan. Meteorological Research Institute.

Summerer, L., 2012. Space and Terrestrial solar power sources for large-scale hydrogen production-a comparison. ESA-Advanced Concepts Study.

Susumu, S., 2009. C101 jaxa research status for space solar power systems. Proceedings of the 9th International Conference on Power Engineering, Nov. 16-20, Kobe, Japan, pp: 135-138.

Wade, N.M., 2001. Distillation plant development and cost update. Desalinization, 136: 3-12.

Wie, B. and C.M. Roithmayr, 2001. Integrated Orbit, Attitude and Structural Control Systems Design for Space Solar Power Satellites. 1st Edn., NASA, Hampton, VA., pp: 124..

Wie, B. and C.M. Roithmayr, 2005. Attitude and orbit control of a very large geostationary solar power satellite. J. Guidance Control Dynamics, 28: 439-451.

Xin, L. and H.Y. Arthur, 2012. Estimation of rain intensity spectra over the continental united states using ground radar-gauge measurements. J. Climate, 25: 1901-1915. 